Article

\title{
Cleaning and Conditioning of Contaminated Core Build-Up Material before Adhesive Bonding
}

\author{
Karsten Klosa ${ }^{1, *}$, Walid Shahid ${ }^{1}$, Milda Aleknonytė-Resch ${ }^{2}$ and Matthias Kern ${ }^{1}[$ \\ 1 Department of Prosthodontics, Propaedeutics and Dental Materials, School of Dentistry, \\ Christian-Albrechts University, 24105 Kiel, Germany; walidshahid@gmx.de (W.S.); \\ mkern@proth.uni-kiel.de (M.K.) \\ 2 Institute of Medical Informatics and Statistics, University Hospital Schleswig-Holstein, Campus Kiel, \\ 24105 Kiel, Germany; resch@medinfo.uni-kiel.de \\ * Correspondence: kklosa@proth.uni-kiel.de; Tel.: +49-431-500-26401
}

Received: 26 May 2020; Accepted: 22 June 2020; Published: 26 June 2020

check for updates

\begin{abstract}
The objective of this study was to evaluate the effects of different cleaning and conditioning procedures after contamination on the tensile bond strength (TBS) of a luting resin to a core build-up composite resin. Specimens $(n=384)$ made of a core build-up material were stored for 3 weeks in $37^{\circ} \mathrm{C}$ water. Half of the specimens were contaminated with saliva and a disclosing silicone and then cleaned either using phosphoric acid, a pumice suspension, air-abrasion with alumina or polishing powder. Surface conditioning was performed by either using a dentin adhesive, a silane containing primer or a composite resin primer, which resulted in 24 unique combinations of 16 specimens per group. Before measuring TBS, half of the specimens of each group were stored in $37^{\circ} \mathrm{C}$ water for $3 \mathrm{~d}$ or were artificially aged for 150 days. Results show that cleaning with pumice or air-abrasion are superior methods compared to using a polishing powder or phosphoric acid. Silane is an inferior conditioning agent compared to composite or dentin primers. Ideally, after contamination, bonding surfaces should be cleaned with a pumice suspension and conditioned with a dentin adhesive. Those surfaces could also be cleaned and conditioned with air-abrasion with alumina particles and a composite resin primer.
\end{abstract}

Keywords: core build-up material; saliva; silicone; cleaning; contamination; conditioning

\section{Introduction}

Fabrication of indirect dental restorations requires specific procedures including preparation of the tooth following explicit rules [1-3]. Due to the fact that cariogenic defects do not follow these rules, teeth often need to be filled using core build-up material prior to the preparation [4]. Whereas conventional cementation methods are relatively technically uncritical, the long-term success of an adhesive cementation depends on many factors such as material-specific conditioning and the adequate cleaning of the bonding surfaces after contamination [5-7]. These factors are well known and examined regarding tooth hard tissues and dental restoration materials such as alloys and ceramics, but little is known of the effects of these factors regarding core build-up materials [8-11].

During preparation and try-in procedures of dental restorations, bonding surfaces, i.e., tooth structures, restoration materials and core build-up materials might be contaminated by saliva [12,13], blood [14], dentin liquor and/or a disclosing silicone [15]. Therefore, the surfaces need to be cleaned and conditioned sufficiently prior to adhesive cementation in order to obtain durable long-term bond strength [16-21].

Cleaning and conditioning of contaminated dental composite surfaces prior to adhesive cementation and the investigation of their influence to the bond strength was the objective of various previous studies [22-33]. Reports on cleaning methods of dental composites are limited to 
repair restorations [24-34]. There is a wide spectrum of cleaning methods for a bonding surface after contamination. Airborne particle abrasion or roughening with a burr lead to a poorer fit of the restorations resulting in poorer bond strengths [34-37].

To the best knowledge of the authors, cleaning methods of core build-up materials prior to adhesive cementation have not been examined to date. Due to the fact that the ingredients of these build-up materials differ from the composition of other composites used for direct restorations (e.g., fillings), the best cleaning method after contamination may also differ. The differences in the composites arise from their type (light curing and/or auto curing) and main focus of either mechanical feasibility or aesthetics. The selected build-up materials in this study were light and auto curing and focus mainly on mechanical feasibility because they are covered by other restorative materials.

Applicable cleaning methods might include using a pumice suspension with a rotating brush, intraoral airborne particle abrasion, using an air polishing powder or etching with phosphoric acid [38]. Scenarios for repairing composite fillings never investigated the influence of disclosing silicone remnants in combination with saliva contamination. Chemical bonding of core build-up materials might be achieved by either using a composite primer [39], which bonds to the organic phase, or by using a silane containing primer [22], which bonds directly to silicate-containing filler particles in the composite resin. Dentin primers might also act as a bond-mediating component to the core build-up material.

Therefore, the purpose of this study was to investigate the influence of different cleaning and surface conditioning methods on the tensile bond strength of luting resins to a core build-up material after contamination with saliva and a disclosing silicone. This study was designed to test the null hypothesis, that the described (1) cleaning methods and (2) conditioning methods have no influence on the bond strength of a luting resin to a contaminated core build-up material and its durability.

\section{Materials and Methods}

\subsection{Specimen Preparation}

Disc-shaped specimens $(n=384)$ of a core build-up material (Luxacore A3, DMG, Hamburg, Germany) were made. A 2-mL syringe was completely filled with the material of choice to create a composite cylinder with a diameter of $8.8 \mathrm{~mm}$, which was sawed into $4 \mathrm{~mm}$ thick pieces after $10 \mathrm{~min}$ self-curing time. All specimens were wet polished with a rotating silicon carbide paper down to 600 grit and then stored for 3 weeks in $37^{\circ} \mathrm{C}$ tap water to obtain water saturation and almost complete polymerization of the material.

\subsection{Surface Contamination}

Half $(n=192)$ of the specimens were contaminated by placing them with their bonding surfaces facing down into human saliva for one minute. The other half of the specimens remained uncontaminated. The donor of the saliva refrained from eating and drinking for $1.5 \mathrm{~h}$ prior to sampling. The saliva was used within $60 \mathrm{~min}$ after harvesting. The saliva was then removed from the specimens by spraying water for $15 \mathrm{~s}$ and then air drying for $15 \mathrm{~s}$ using an air blower with oil-free air. Afterwards, the bonding surfaces were pressed into a disclosing silicone (Fit Checker Black, GC Europe, Leuven, Belgium), removed after 5 min with any visible remnants manually detached.

\subsection{Surface Cleaning}

Four different cleaning methods were used to each treat 48 contaminated and 48 not contaminated specimens:

Phosphoric acid (37\%, Etching Gel-Medium viscosity, DMG, Hamburg, Germany) was applied to the bonding surface. It was removed after $15 \mathrm{~s}$ by spraying water for $15 \mathrm{~s}$ and the bonding surface was dried with compressed, oil-free air for $15 \mathrm{~s}$. 
1. Pumice powder was mixed with a $0.9 \% \mathrm{NaCl}$-solution and was applied onto the bonding surface using a rotating brush for $15 \mathrm{~s}$ at a rotation speed of $2000 \mathrm{rpm}$. Afterwards, the pumice suspension was removed by spraying water for $15 \mathrm{~s}$ and then the bonding surface was dried with oil-free compressed air for $15 \mathrm{~s}$.

2. Airborne particle abrasion: the bonding surface was marked with a red marker and then air-abraded with $50 \mu \mathrm{m}$ alumina particles from a distance of $10 \mathrm{~mm}$ and a pressure of 0.5 bar until no colour remnants were visible. The remaining alumina particles were removed with spraying water for $15 \mathrm{~s}$ and then the bonding surface was dried with compressed, oil-free air for $15 \mathrm{~s}$.

3. The dry bonding surface was cleaned with a sodium bicarbonate prophylaxis spray (Cavitron Prophy-Jet Prophy Powder, Dentsply DeTrey, Constance, Germany) using an air polisher (Cleanjet, Yoshida Dental, Tokyo, Japan) from a distance of $10 \mathrm{~mm}$ and a pressure of $2.5 \mathrm{bar}$ for $15 \mathrm{~s}$. The remaining prophylaxis powder particles were removed by spraying water for $15 \mathrm{~s}$ and then the bonding surface was dried with compressed, oil-free air for $15 \mathrm{~s}$.

\subsection{Surface Conditioning}

The specimens in each of the four surface cleaning subgroups were randomly assigned to three smaller groups of 16 specimens per group. A different primer was used on each of the three smaller groups, as specified by the manufacturer:

1. A dentin adhesive (Optibond FL, Kerr Hawe, Bioggio, Switzerland), which is used as follows: The Optibond FL Primer was applied to the bonding surface using a disposable brush. After a dwell time of $30 \mathrm{~s}$, the remaining liquid was removed by using an oil-free air blower for $15 \mathrm{~s}$. Then, the Optibond FL Adhesive was applied using a disposable brush and was blown after $15 \mathrm{~s}$ using compressed, oil-free air for another $15 \mathrm{~s}$. Afterwards, the adhesive was polymerized for $30 \mathrm{~s}$ with a dental curing light at a light intensity of $650 \mathrm{~mW} / \mathrm{cm}^{2}$ (Demetron Optilux 501, Kerr, Danbury, CT, USA) from a distance of $10 \mathrm{~mm}$.

2. A silane containing primer (Monobond Plus, Ivoclar Vivadent, Schaan, FL, Liechtenstein) was applied to the bonding surface using a disposable brush and after a dwell time of $60 \mathrm{~s}$ was dried with compressed, oil-free air for $15 \mathrm{~s}$.

3. A composite resin primer (Ecusit-Composite Repair, DMG, Hamburg, Germany) was applied using a disposable brush. After a dwell time of $60 \mathrm{~s}$ is was gently blown using compressed, oil-free air for $15 \mathrm{~s}$ and light-cured for $20 \mathrm{~s}$ using a dental curing light at a light intensity of $650 \mathrm{~mW} / \mathrm{cm}^{2}$ (Demetron Optilux 501, Kerr, Danbury, CT, USA) from a distance of $10 \mathrm{~mm}$.

\subsection{Bonding and Storage Conditions}

Plexiglas tubes with an inner diameter of $3.2 \mathrm{~mm}$ (corresponds to a bonding surface of $0.08 \mathrm{~cm}^{2}$ ) were filled with dual-curing composite resin (Luxacore A3, DMG, Hamburg, Germany). After curing time (5 min), the filled tubes were bonded with a luting composite resin (Vitique White, DMG, Hamburg, Germany) to the core build-up composite surface using an alignment apparatus under a load of $750 \mathrm{~g}$ [40]. This apparatus ensured that the tube axis was perpendicular to the surface. After excess resin was removed, an air blocking gel (Vitique Try-In-Paste Transparent, DMG, Hamburg, Germany) was applied around the bonding margins. After $5 \mathrm{~min}$, the bonded specimens were light-cured for $20 \mathrm{~s}$ from two opposite sides with a dental curing light at a light intensity of $650 \mathrm{~mW} / \mathrm{cm}^{2}$ (Demetron Optilux 501, Kerr, Danbury, CT, USA), then further cured in a light-curing unit (Heraflash, Heraeus Kulzer, Hanau, Dresden, Germany) for $90 \mathrm{~s}$, placed at room temperature for $10 \mathrm{~min}$, and then stored in $37^{\circ} \mathrm{C}$ tap water after removing the air blocking gel with water spray for $15 \mathrm{~s}$. With regard to contamination presence, the four surface cleaning methods and three surface conditioning primers resulted in 24 test groups. For each test group, 16 specimens were bonded. Half of these bonded specimens were stored in tap water $\left(37^{\circ} \mathrm{C}\right)$ for 3 days and the other half for 150 days with artificial aging, where water storage 
was interrupted by 37,500 thermal cycles $\left(5\right.$ to $\left.55^{\circ} \mathrm{C}\right)$ with a dwell time of $30 \mathrm{~s}$. Composition and batch numbers of the materials are shown in Table 1.

Table 1. List of used materials and their characteristics.

\begin{tabular}{cccc}
\hline Material & Main Composition & Manufacturer & Batch No. \\
\hline Luxacore A3 & Acrylate containing core build-up material & DMG & 643862 \\
Vitique White & Acrylate containing dual curing luting resin & DMG & 632877 \\
Vitique Try-In-Paste & Glycerin based air blocking gel & DMG & 633912 \\
Fit Checker Black & Si/Sn cont. Silicone & GC & 045487 \\
Etching Gel & A7\% Phosphoric acid/water cont. gel & DMG & 637056 \\
Ecusit Composite Repair & Acrylate containing composite primer & DMG & 637728 \\
& Ethanol, water, silane methacrylate, & Ivoclar Vivadent & M35022 \\
Monobond Plus & phosphoric acid methacrylate, & & $25881 \mathrm{E}$ \\
& sulphide methacrylate & & \\
& Hydroxyethylmethacrylate, disodium & Kerr Hawe & \\
Optibond FL & hexafluorosilicate, ethyl alcohol & &
\end{tabular}

To sum up the methods, a total of 24 test groups with 16 specimens per group were examined. The groups consisted of all possible unique contamination status, surface cleaning methods and conditioning primers. Test groups were divided in subgroups with $3 \mathrm{~d}$ short-term and $150 \mathrm{~d}$ long- term storage times with 8 specimens each. A visual overview of the different groups can be seen in Table 2 .

Table 2. Median tensile bond strength (TBS) by cleaning, conditioning and contamination status.

\begin{tabular}{|c|c|c|c|c|}
\hline \multirow[b]{2}{*}{ Contamination Status. } & \multirow[b]{2}{*}{ Cleaning } & \multirow[b]{2}{*}{ Conditioning } & \multicolumn{2}{|c|}{ Median TBS (MPa) } \\
\hline & & & $\begin{array}{l}\text { Short-Term } \\
\text { (3 Days) }\end{array}$ & $\begin{array}{l}\text { Long-Term } \\
\text { (150 Days) }\end{array}$ \\
\hline \multirow{12}{*}{ No Contamination } & \multirow{3}{*}{ Phosphoric Acid } & Dentin Primer & 21.3 & 16.2 \\
\hline & & Silane & 12.7 & 10.7 \\
\hline & & Composite Primer & 22.2 & 18.7 \\
\hline & \multirow{3}{*}{ Pumice Suspension } & Dentin Primer & 20.8 & 16.5 \\
\hline & & Silane & 17.8 & 19.2 \\
\hline & & Composite Primer & 13.3 & 16.8 \\
\hline & \multirow{3}{*}{ Air Abrasion } & Dentin Primer & 21.0 & 21.6 \\
\hline & & Silane & 15.3 & 12.1 \\
\hline & & Composite Primer & 18.3 & 19.5 \\
\hline & \multirow{3}{*}{ Air Polishing Powder } & Dentin Primer & 17.3 & 11.6 \\
\hline & & Silane & 10.2 & 4.9 \\
\hline & & Composite Primer & 26.6 & 12.8 \\
\hline \multirow{12}{*}{ Contamination } & \multirow{3}{*}{ Phosphoric Acid } & Dentin Primer & 15.9 & 10.3 \\
\hline & & Silane & 8.0 & 7.3 \\
\hline & & Composite Primer & 19.3 & 15.8 \\
\hline & \multirow{3}{*}{ Pumice Suspension } & Dentin Primer & 14.9 & 16.0 \\
\hline & & Silane & 14.1 & 14.6 \\
\hline & & Composite Primer & 12.7 & 14.9 \\
\hline & \multirow{3}{*}{ Air Abrasion } & Dentin Primer & 18.1 & 19.9 \\
\hline & & Silane & 21.2 & 16.2 \\
\hline & & Composite Primer & 21.4 & 17.5 \\
\hline & \multirow{3}{*}{ Air Polishing Powder } & Dentin Primer & 28.6 & 12.5 \\
\hline & & Silane & 18.8 & 10.2 \\
\hline & & Composite Primer & 24.1 & 13.4 \\
\hline
\end{tabular}

\subsection{Debonding and Statistical Analysis}

At the end of the storage periods, tensile bond strength (TBS) was measured in a universal testing apparatus (Z010, Zwick, Ulm, Dresden, Germany) at a crosshead speed of $2 \mathrm{~mm} / \mathrm{min}$ using a 
chain loop alignment which provided a moment-free axial load application. The fractured interfaces of the debonded specimens were examined using a light microscope (LM, Zeiss S7, Carl Zeiss AG, Oberkochen, Germany) at 30× magnification to calculate the fracture mode of each specimen as either adhesive or cohesive (failure in tube composite, the specimen composite or the bonding resin). Fractional allocation measured in percentages of adhesive and cohesive failure mode was possible in case of a mixed adhesive and cohesive failure mode. The arithmetic mean of both failure modes was then determined for each subgroup $(n=8)$. After sputtering a conductive gold layer with a thickness of approximately $15 \mathrm{~nm}$ as measured with a quartz crystal film thickness monitor (Leica EM QSG 100, Wetzlar, Germany), three representative samples of each group were examined in a scanning electron microscope (SEM, XL 30 CP, Philips, Kassel, Germany) with an acceleration voltage of $15 \mathrm{KeV}$.

Statistical analysis using the Shapiro-Wilk test showed that the data of some groups were not normally distributed. Therefore, further analysis was performed using the Kruskal-Wallis-Test followed by multiple pair-wise comparisons of the groups using the Wilcoxon rank sum test, corrected with the Bonferroni-Holm procedure for multiple comparisons within each rank sum test. The overall significance level was adjusted for multiple testing according to Bonferroni by the number of unique cleaning-conditioning combinations, resulting in the level of significance of $p \leq 0.0042$.

\section{Results}

Boxplots of TBS for all test groups after short-term storage are shown in Figure 1a and of all test groups after long-term storage in Figure 1b. The median TBSs of each test group are depicted in Table 2. The $p$-values of all performed group tests using the Wilcoxon rank sum test using Bonferroni-Holm correction can be found in Appendix A.

Generally, contamination resulted in lower median TBS, although it was statistically significant only in the test group treated with air polishing powder and silane conditioning after three days (Table A1). When comparing the storage conditions (short-term storage versus long-term storage), statistically significant $(p \leq 0.0042)$ lower TBS was detected only in the groups that had been cleaned with air polishing powder and treated with a dentin primer or a composite primer when in a not contaminated environment and any primer in a contaminated environment (Table A2).

The comparison of cleaning and conditioning methods in the long-term subgroup led to the following results: prior to conditioning the surface with a dentin adhesive, air-abrading the contaminated surface provided statistically significantly $(p \leq 0.0042)$ higher median TBS than air-polishing with prophylaxis powder, regardless of the contamination status. Moreover, cleaning the surface with phosphoric acid provided statistically significantly lower TBS than pumice suspension in a contaminated environment using a dentin primer. Phosphoric acid also led to a statistically significant lower TBS than air-abrasion in a contaminated environment using either dentin or silane primers. In fact, air abrasion exhibited the highest median TBS (16.2-19.9 MPa) in the contaminated subgroup regardless of the primer used (see Table 2). Using air abrasion, a statistically significant difference in median TBS in a contaminated environment was also observed in comparison to air polishing powder using a dentin primer. No statistically significant differences between the cleaning methods were observed after long-term storage when conditioning the bonding surface with a composite primer (Table A3).

Regarding conditioning methods in the long-term time period, a dentin primer resulted in statistically significantly lower median TBS than the other primers after cleaning with air-abrasion in an uncontaminated environment. Specimens treated with a combination of phosphoric acid and a composite primer achieved significantly higher bond strengths compared to the other test groups in a contaminated environment (Table A4).

The results of the failure mode analysis using light microscopy (LM) and scanning electron microscopy (SEM) are shown in Figure 2a for short-term storage and in Figure 2b for long-term storage and artificial aging. Contamination resulted in more adhesive bonding failures, whereas adequate cleaning resulted in more cohesive bonding failures. The examination of typical samples in the SEM 
verified the failure modes detected with the LM in all groups. Figure 3 shows SEM photographs with a typical example of a pure adhesive failure mode (Figure $3 a, b$ ) as well as a mixed adhesive and cohesive failure mode (Figure 3c,d). As can be seen in Figure 3a, the surface within the circle in the adhesive failure mode is flat and smooth, which is elaborated in the magnification seen in Figure $3 \mathrm{~b}$. Figure $3 c$, however, depicts a different scenario with a small smooth surface indicating an adhesive failure mode, which transitions into cohesive fracture lines running from the lower left area of the visible remnant of the luting resin to the right and therefore is most likely the origin of the failure in this specific sample. The transition zone between adhesive and cohesive failure modes can be seen in the high magnification SEM micrograph (Figure 3d). In this example, $40 \%$ of the failure is attributed to an adhesive and $60 \%$ to a cohesive mode.

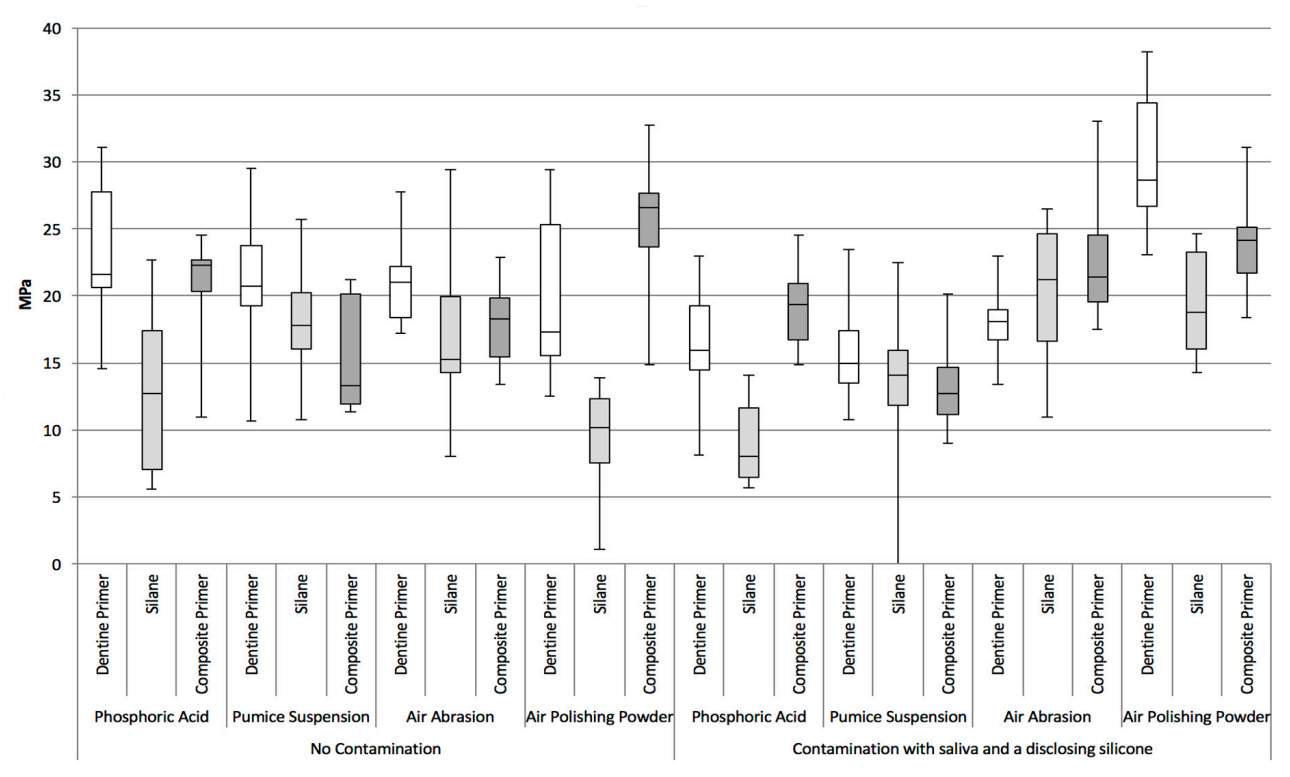

(a)

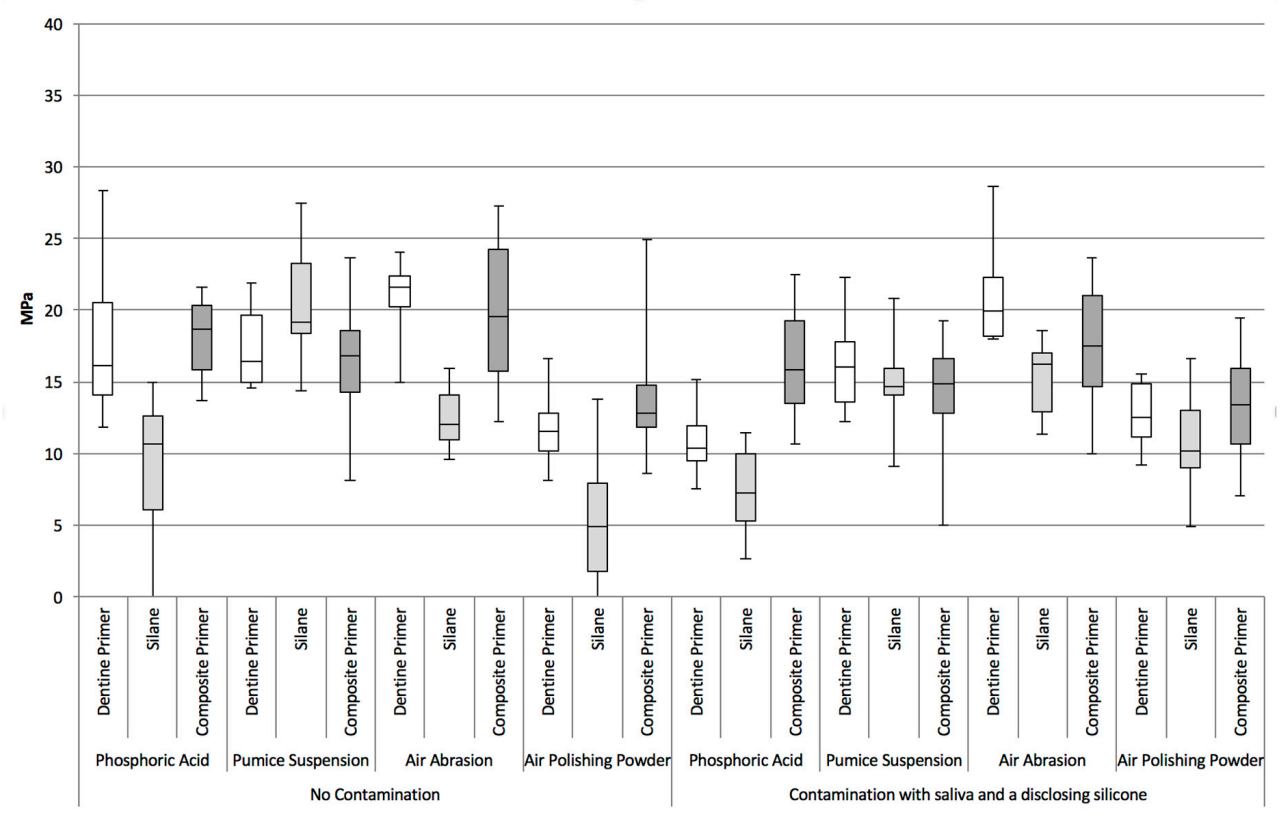

(b)

Figure 1. (a) Boxplots of TBS for all test groups after short-term storage (3 days); (b) Boxplots of TBS for all test groups after long-term storage in $37^{\circ} \mathrm{C}$ tap water for 150 days with artificial aging. 


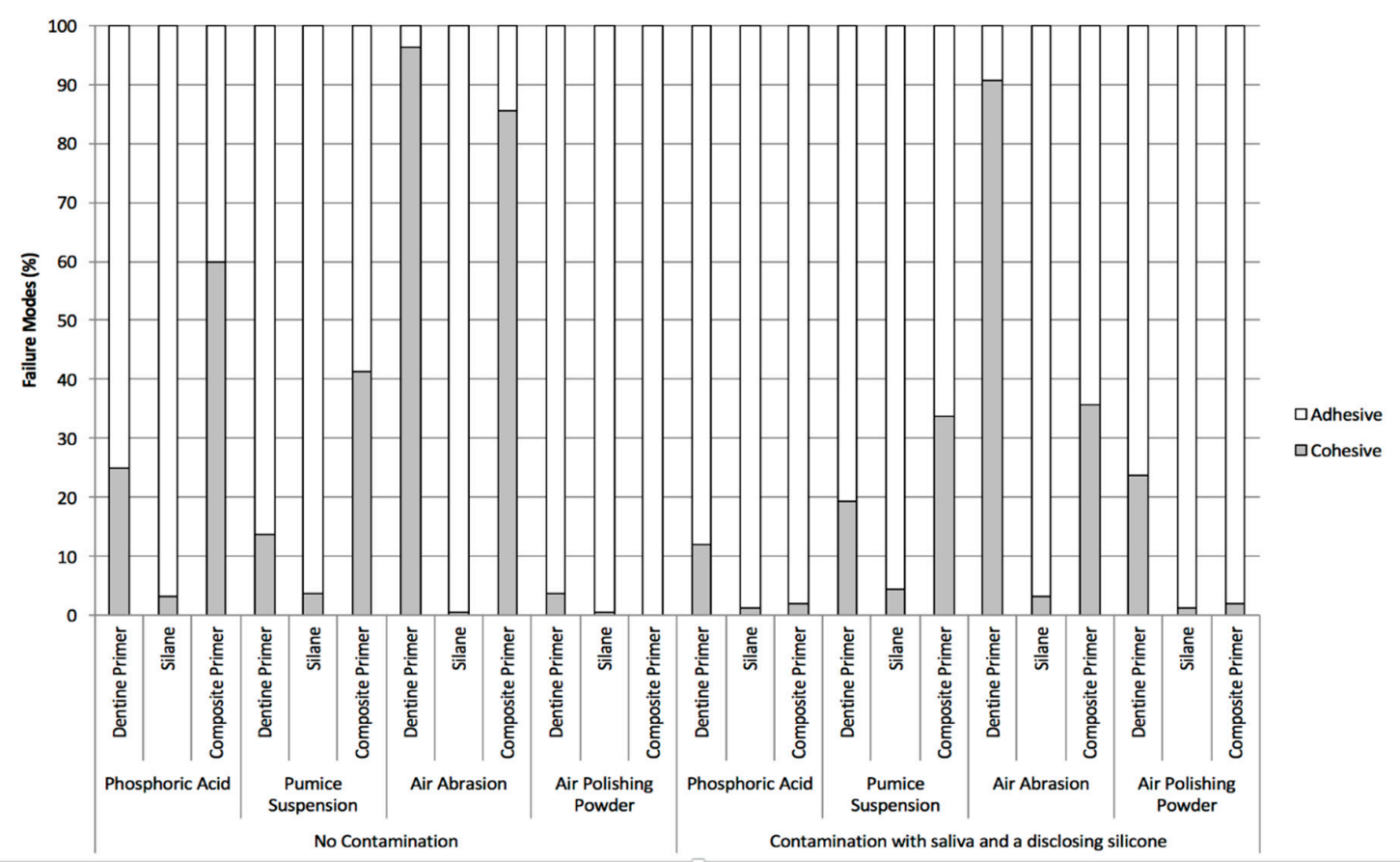

(a)

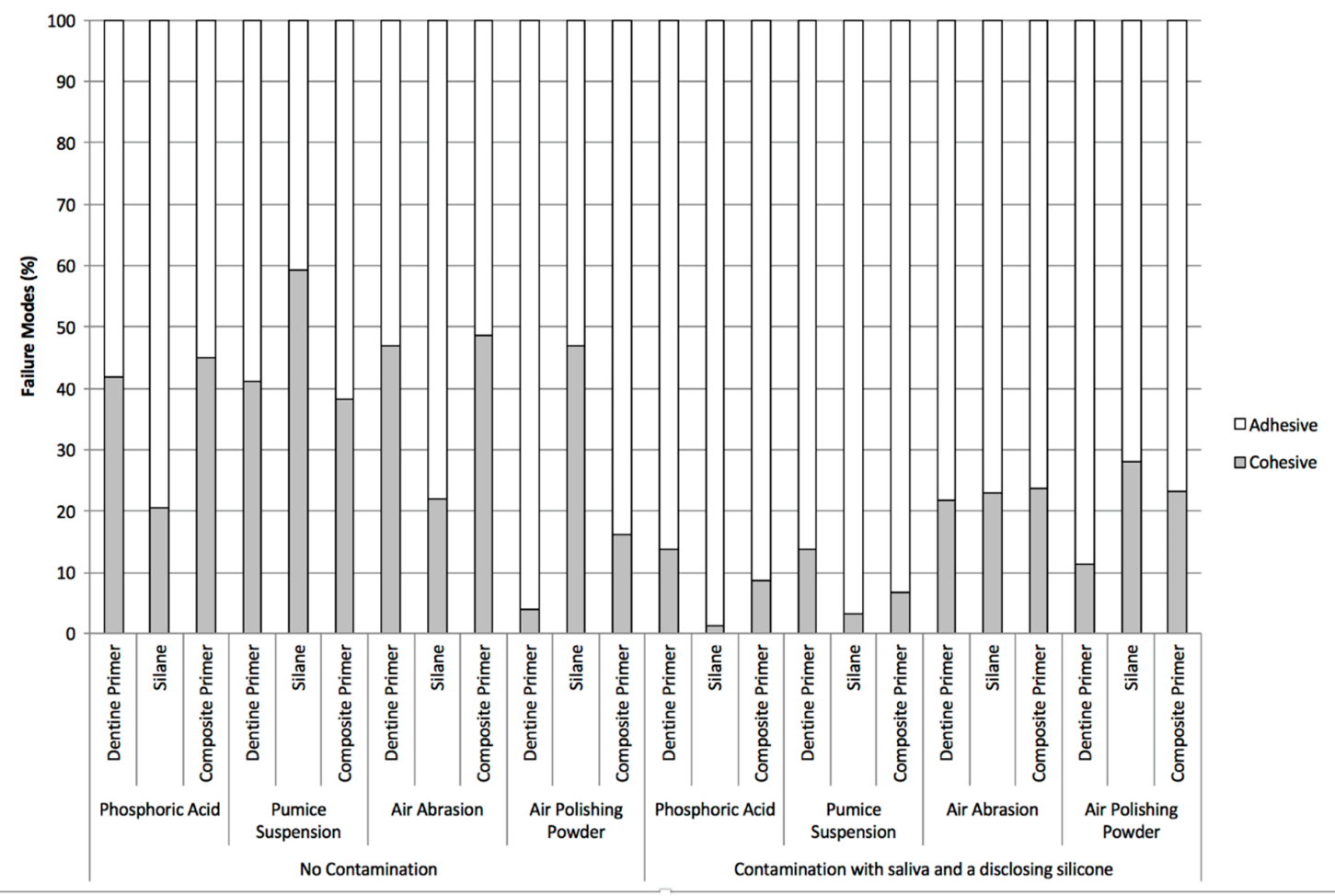

(b)

Figure 2. Type of bonding failure modes of test groups after (a) short-term storage in $37^{\circ} \mathrm{C}$ tap water for 3 days and (b) for 150 days with artificial aging as identified with a light microscope at 30× magnification and calculated in percentage of the bonding area. 


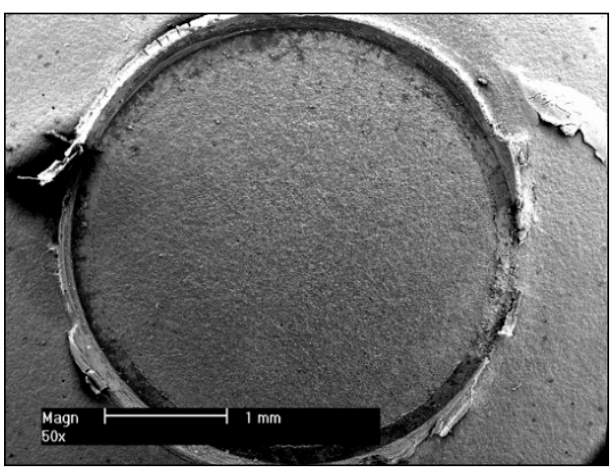

(a)

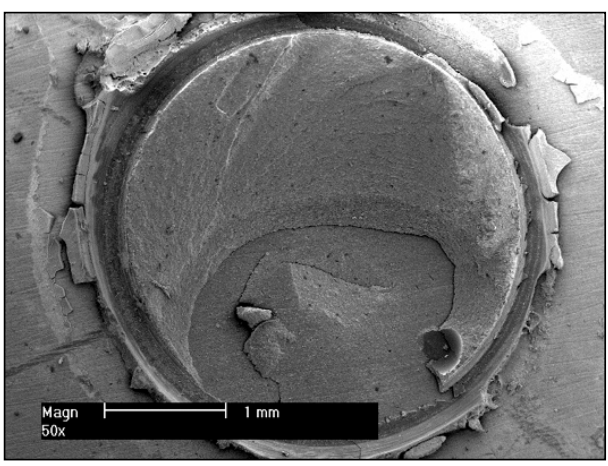

(c)

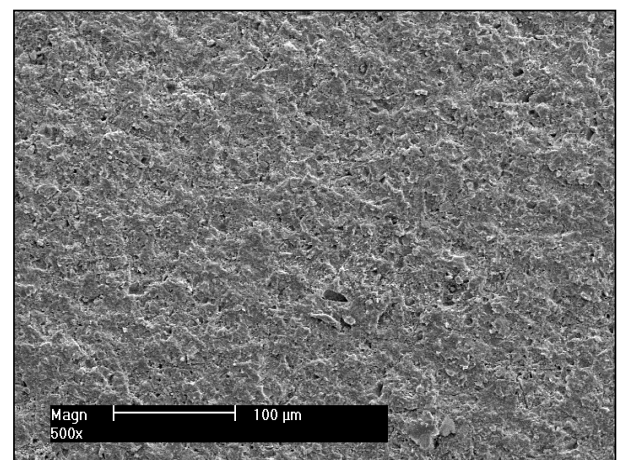

(b)

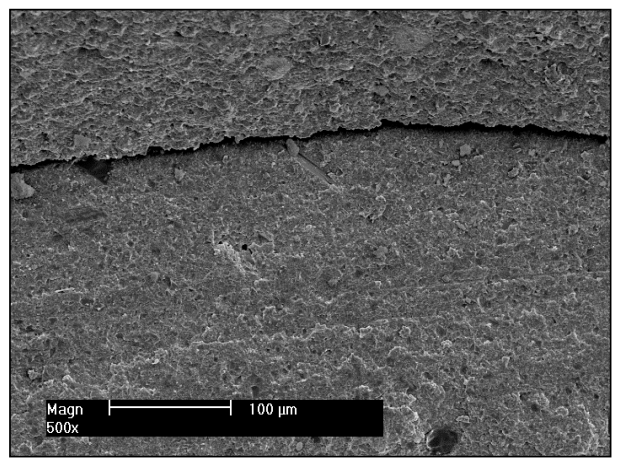

(d)

Figure 3. (a) A representative example of a purely adhesive failure mode in a debonded specimen. SEM micrograph: low magnification; (b) detailed SEM micrograph: high magnification of (a); (c) A representative example of a mixed adhesive and cohesive failure mode in a debonded specimen. SEM micrograph: low magnification; (d) detailed SEM micrograph: high magnification of (c).

\section{Discussion}

Four common cleaning methods were chosen for investigation in this study [12,15,41,42]. They were examined under two conditions-with contamination and without contamination-as well as two different time points-short-term (3 days) and long-term (150 days with artificial aging). Three surface conditioning methods were applied to each of the cleaning methods. Two of these three conditioning methods are principle methods for bonding to composite resins (bonding to the inorganic fillers or the organic phase) have previously been investigated in other studies for intra-oral repair procedures of composite fillings $[23,39,43]$. In most cases of adhesive cementation of dental restorations, conditioning the dentin with a dentin adhesive is necessary [44]. Hence, a dentin adhesive was chosen as a third option for conditioning build-up material before adhesive cementation, also because it is widespread and well known to almost all dentists. This study stands out as it investigated the influence of disclosing silicone remnants in combination with saliva contamination for various scenarios for repairing composite build-ups.

After long-term storage simulating the exposition in the oral environment, the bond strength decreased in 16 of the 24 test groups. This might be caused by water saturation and artificial aging, which leads to hydrolytic degradation of the used primers [45,46]. Considering the cleaning methods with contamination, air-abrasion and brushing with a pumice suspension lead to higher TBS than etching with phosphoric acid or using an air-polishing device in most scenarios. Air-abrasion causes pronounced micro roughening compared to air-polishing. Obviously, remnants of the used contaminations require a thorough mechanical treatment to be removed sufficiently. 
Only one statistically significant difference in median TBS between contaminated and not contaminated in the 24 subgroups (air polishing powder cleaning and silane conditioning) could be observed. This is a limitation of our study, which is mainly caused by the low level of significance. Nevertheless, in our application scenario, i.e., bonding after the removal of the provisional restoration, cleaning is always necessary, since the adhesive surface would be contaminated by biofilm and/or remnants of the provisional cement.

Our findings compare and reproduce the results of other studies well, e.g., etching a ceramic bonding surface with phosphoric acid was not appropriate to remove remnants of a disclosing silicone and does not provide high TBS long-term. This can be explained by the inability of phosphoric acid to dissolve silicone oils [12], thus the combination of phosphoric acid and silane should be avoided. Another study showed similar results when cleaning a pre-etched lithium disilicate ceramic after contamination with a disclosing silicone [12]. The relatively low kinetic energy of the air-polishing device or the chemical composition might be responsible for an insufficient cleaning resulting in lower TBS long-term as our study showed the lowest median TBS of air polishing powder regardless of the contamination status and conditioning used in comparison to other cleaning methods.

The observed lack of potential of a silane to promote sufficient bonding of a luting resin to the core build-up material stands in contrast to the findings in other studies investigating intra-oral repairing procedures of composite fillings [22]. It might be explained by a different composition of core build-up materials compared to composites for direct fillings. For aesthetic and mechanical reasons, filling composites contain a relatively high amount of inorganic fillers made of silicates [43]. The composition of the used core build-up material contains a lower amount of silicates, which might result in fewer bindings of a silane to the bonding surface [47,48]. A similar effect was found in a recent study investigating resin bonding techniques to CAD/CAM resin composites [49].

To sum up, the following conclusions can be drawn from our study: (1) Cleaning a core build-up material bonding surface after contamination with saliva and a disclosing silicone with alumina particle air-abrasion or a rotating brush with pumice suspension resulted in statistically significantly higher TBS than cleaning with an air-polishing device or etching with phosphoric acid. (2) In some cases, using a silane containing primer for conditioning the bonding surface of a core build-up material resulted in statistically significantly lower TBS compared to conditioning with a dentin primer or a composite resin primer. Due to the observed statistically significant differences, the null hypothesis cleaning and conditioning methods have no influence on bond strength, must be rejected. After contamination with saliva and a disclosing silicone, bonding surfaces of a core build-up material should be cleaned with a rotating brush and a pumice suspension and conditioned with a dentin adhesive, which is conveniently required for adhesive bonding to tooth structure nonetheless. Using a less practical way, these surfaces could also be cleaned and conditioned with intraoral air-abrasion with alumina particles and a composite resin primer.

Author Contributions: Conceptualization, K.K. and M.K.; Methodology, K.K. and M.K.; Validation, K.K., W.S., and M.K.; Formal analysis, K.K. and M.A.-R.; Investigation, W.S.; Resources, K.K. and M.K.; Data curation, K.K.; Writing —original draft preparation, K.K.; Writing—review and editing, M.K. and M.A.-R.; Visualization, K.K., M.A.-R. and W.S.; Supervision, M.K.; Project administration, K.K.; Funding acquisition, K.K.; All authors have read and agreed to the published version of the manuscript.

Funding: This research received no external funding.

Acknowledgments: This research was supported with materials by DMG Chemisch-Pharmazeutische Fabrik $\mathrm{GmbH}$ (Hamburg, Germany). We would like to acknowledge Gunnar Meyer for his help on literature research.

Conflicts of Interest: The authors declare no conflict of interest. 


\section{Appendix A}

Table A1. Comparison of each test group with and without contamination using Wilcoxon rank sum test with Bonferroni-Holm procedure for multiple testing. Time periods were tested separately. Overall significance level adjusted for multiple testing according to Bonferroni $(p \leq 0.0042)$. Significant results are in bold and marked with $(*)$.

\begin{tabular}{ccccccc}
\hline & \multicolumn{3}{c}{ Short-Term (3 Days) } & \multicolumn{2}{c}{ Long-Term (150 Days, Artificial Aging) } \\
\cline { 2 - 6 } & Dentin Primer & Silane & Composite Primer & Dentin Primer & Silane & Composite Primer \\
\hline Phosphoric Acid & 0.19487 & 0.38228 & 0.44180 & 0.00454 & 0.27863 & 0.44180 \\
\hline Pumice Suspension & 0.13038 & 0.08298 & 0.50536 & 0.64538 & 0.03120 & 0.56324 \\
\hline Air Abrasion & 0.10331 & 0.38228 & 0.04584 & 0.57374 & 0.03792 & 0.44180 \\
\hline Air Polishing Powder & 0.01041 & $\mathbf{0 . 0 0 0 1 6 *}$ & 0.27863 & 0.44180 & 0.05168 \\
\hline
\end{tabular}


Table A2. Comparison of unique contamination, cleaning and conditioning method combinations over time. Each unique combination was tested separately using Wilcoxon rank sum test with Bonferroni-Holm procedure for multiple testing. Overall significance level adjusted for multiple testing according to Bonferroni $(p \leq 0.0042)$. Significant results are in bold and marked with $\left(^{*}\right)$.

\begin{tabular}{|c|c|c|c|}
\hline \multirow{12}{*}{ No Contamination } & \multirow{3}{*}{ Phosphoric Acid } & Dentin Primer & 0.23450 \\
\hline & & Silane & 0.27863 \\
\hline & & Composite Primer & 0.06496 \\
\hline & \multirow{3}{*}{ Pumice Suspension } & Dentin Primer & 0.10490 \\
\hline & & Silane & 0.23450 \\
\hline & & Composite Primer & 0.87848 \\
\hline & \multirow{3}{*}{ Air Abrasion } & Dentin Primer & 0.87473 \\
\hline & & Silane & 0.08298 \\
\hline & & Composite Primer & 0.57374 \\
\hline & \multirow{3}{*}{ Air Polishing Powder } & Dentin Primer & $0.00186^{*}$ \\
\hline & & Silane & 0.09241 \\
\hline & & Composite Primer & 0.00186 * \\
\hline \multirow{12}{*}{ Contamination } & \multirow{3}{*}{ Phosphoric Acid } & Dentin Primer & 0.01476 \\
\hline & & Silane & 0.32821 \\
\hline & & Composite Primer & 0.16053 \\
\hline & \multirow{3}{*}{ Pumice Suspension } & Dentin Primer & 0.79845 \\
\hline & & Silane & 0.56324 \\
\hline & & Composite Primer & 0.56324 \\
\hline & \multirow{3}{*}{ Air Abrasion } & Dentin Primer & 0.08298 \\
\hline & & Silane & 0.08298 \\
\hline & & Composite Primer & 0.08298 \\
\hline & \multirow{3}{*}{ Air Polishing Powder } & Dentin Primer & $0.00016^{*}$ \\
\hline & & Silane & $0.00274^{*}$ \\
\hline & & Composite Primer & $0.00062 *$ \\
\hline
\end{tabular}


Table A3. Comparison of cleaning methods by unique contamination status and conditioning combinations. Each unique combination and time period was tested separately using Wilcoxon rank sum test with Bonferroni-Holm procedure for multiple testing. Overall significance level adjusted for multiple testing according to Bonferroni $(p \leq 0.0042)$. Significant results are in bold and marked with $(*)$.

\begin{tabular}{|c|c|c|c|c|c|c|c|c|}
\hline & & & \multicolumn{3}{|c|}{ Short-Term (3 Days) } & \multicolumn{3}{|c|}{ Long-Term (150 Days, Artificial Aging) } \\
\hline & & & $\begin{array}{c}\text { Phosphoric } \\
\text { Acid }\end{array}$ & $\begin{array}{c}\text { Pumice } \\
\text { Suspension }\end{array}$ & Air Abrasion & $\begin{array}{l}\text { Phosphoric } \\
\text { Acid }\end{array}$ & $\begin{array}{c}\text { Pumice } \\
\text { Suspension }\end{array}$ & Air Abrasion \\
\hline \multirow{9}{*}{$\begin{array}{c}\text { No } \\
\text { Contamination }\end{array}$} & \multirow{3}{*}{ Dentin Primer } & Pumice Suspension & 0.79275 & - & - & 0.95913 & - & - \\
\hline & & Air Abrasion & 0.79275 & 0.79275 & - & 0.15646 & 0.03100 & - \\
\hline & & Air Polishing Powder & 0.79275 & 0.79275 & 0.79275 & 0.01399 & 0.00559 & $0.00186^{*}$ \\
\hline & \multirow{3}{*}{ Silane } & Pumice Suspension & 0.26076 & - & - & 0.00186 * & - & - \\
\hline & & Air Abrasion & 0.41795 & 0.64538 & - & 0.32821 & $0.00186 *$ & - \\
\hline & & Air Polishing Powder & 0.53016 & 0.02098 & 0.02098 & 0.18604 & $0.00186 *$ & 0.01504 \\
\hline & \multirow{3}{*}{ Composite Primer } & Pumice Suspension & 0.07111 & - & - & 0.60643 & - & - \\
\hline & & Air Abrasion & 0.15646 & 0.32821 & - & 0.72090 & 0.32106 & - \\
\hline & & Air Polishing Powder & 0.07483 & 0.02797 & 0.07111 & 0.14965 & 0.60643 & 0.14965 \\
\hline \multirow{9}{*}{ Contamination } & \multirow{3}{*}{ Dentin Primer } & Pumice Suspension & 0.79845 & - & - & 0.00218 * & - & - \\
\hline & & Air Abrasion & 0.53016 & 0.35175 & - & $0.00047^{*}$ & 0.03375 & - \\
\hline & & Air Polishing Powder & $0.00047^{*}$ & $0.00062 *$ & $0.00047^{*}$ & 0.10490 & 0.03375 & $0.00047^{*}$ \\
\hline & \multirow{3}{*}{ Silane } & Pumice Suspension & 0.05986 & - & - & 0.00823 & - & - \\
\hline & & Air Abrasion & $0.00326 *$ & 0.05688 & - & $0.00186 *$ & 0.71299 & - \\
\hline & & Air Polishing Powder & $0.00093^{*}$ & 0.04134 & 0.67420 & 0.22672 & 0.06041 & 0.06041 \\
\hline & \multirow{3}{*}{ Composite Primer } & Pumice Suspension & 0.04134 & - & - & 0.55752 & - & - \\
\hline & & Air Abrasion & 0.19263 & 0.01399 & - & 0.64538 & 0.53959 & - \\
\hline & & Air Polishing Powder & 0.04219 & 0.00653 * & 0.50536 & 0.53959 & 0.64538 & 0.53959 \\
\hline
\end{tabular}

Table A4. Comparison of conditioning approaches by unique contamination status and method combinations. Each unique combination and time period was tested separately using Wilcoxon rank sum test with Bonferroni-Holm procedure for multiple testing. Overall significance level adjusted for multiple testing according to Bonferroni $(p \leq 0.0042)$. Significant results are in bold and marked with $\left(^{*}\right)$.

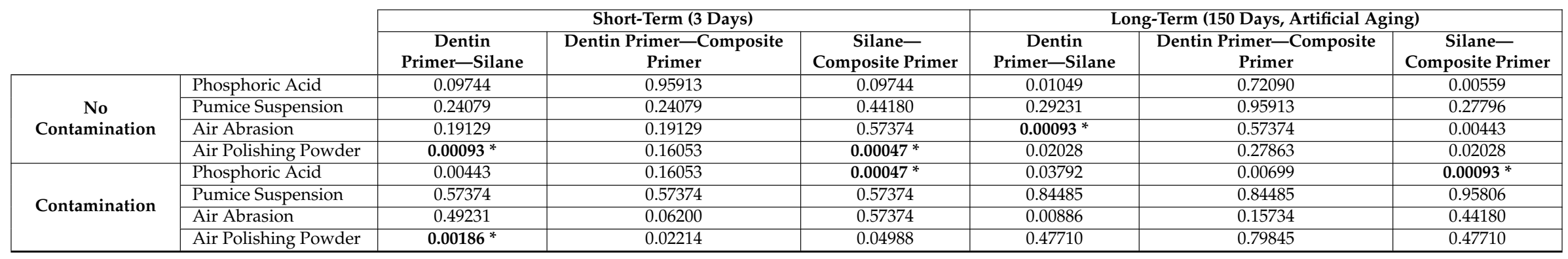




\section{References}

1. Ahlers, M.O.; Mörig, G.; Blunck, U.; Hajto, J.; Pröbster, L.; Frankenberger, R. Guidelines for the preparation of CAD/CAM ceramic inlays and partial crowns. Int. J. Comput. Dent. 2009, 12, 309-325. [PubMed]

2. Maxwell, A.W.; Blank, L.W.; Pelleu, G.B. Effect of crown preparation height on the retention and resistance of gold castings. Gen. Dent. 1990, 38, 200-202. [PubMed]

3. Sasse, M.; Krummel, A.; Klosa, K.; Kern, M. Influence of restoration thickness and dental bonding surface on the fracture resistance of full-coverage occlusal veneers made from lithium disilicate ceramic. Dent. Mater. 2015, 31, 907-915. [CrossRef] [PubMed]

4. Wegner, S.; Wolfart, S.; Kern, M. In vivo study of the marginal integrity of composite resin buildups after full crown preparation. J. Adhes. Dent. 2004, 6, 151-155. [PubMed]

5. Quaas, A.C.; Heide, S.; Freitag, S.; Kern, M. Influence of metal cleaning methods on the resin bond strength to NiCr alloy. Dent. Mater. 2005, 21, 192-200. [CrossRef]

6. Attia, A.; Lehmann, F.; Kern, M. Influence of surface conditioning and cleaning methods on resin bonding to zirconia ceramic. Dent. Mater. 2011, 27, 207-213. [CrossRef]

7. Takahashi, A.; Takagaki, T.; Wada, T.; Uo, M.; Nikaido, T.; Tagami, J. The effect of different cleaning agents on saliva contamination for bonding performance of zirconia ceramics. Dent. Mater. 2018, 37, 734-739. [CrossRef]

8. Blatz, M.B.; Sadan, A.; Kern, M. Resin-ceramic bonding: A review of the literature. J. Prosthet Dent. 2003, 89, 268-274. [CrossRef] [PubMed]

9. Dbradovic-Djuricic, K.; Medic, V.; Dodic, S.; Gavrilov, D.; Antonijevic, D.; Zrilic, M. Dilemmas in zirconia bonding: A review. Srp Arh Celok Lek 2013, 141, 395-401. [CrossRef] [PubMed]

10. Du Preez, I.C.; Ferreira, M.R. Resin-bonded and resin-veneered dental prostheses: A review of resin bonding to metal. J. Dent. Assoc. S. Afr. 1993, 48, 671-677. [PubMed]

11. Papia, E.; Larsson, C.; du Toit, M.; Vult von Steyern, P. Bonding between oxide ceramics and adhesive cement systems: A systematic review. J. Biomed. Mater. Res. B Appl. Biomater. 2014, 102, 395-413. [CrossRef]

12. Klosa, K.; Wolfart, S.; Lehmann, F.; Wenz, H.J.; Kern, M. The effect of storage conditions, contamination modes and cleaning procedures on the resin bond strength to lithium disilicate ceramic. J. Adhes. Dent. 2009, 11, 127-135. [PubMed]

13. Bijelic-Donova, J.; Flett, A.; Lassila, L.V.J.; Vallittu, P.K. Immediate repair bond strength of fiber-reinforced composite after saliva or water contamination. J. Adhes. Dent. 2018, 20, 205-212.

14. Phark, J.H.; Duarte, S., Jr.; Kahn, H.; Blatz, M.B.; Sadan, A. Influence of contamination and cleaning on bond strength to modified zirconia. Dent. Mater. 2009, 25, 1541-1550. [CrossRef] [PubMed]

15. Zhang, S.; Kocjan, A.; Lehmann, F.; Kosmac, T.; Kern, M. Influence of contamination on resin bond strength to nano-structured alumina-coated zirconia ceramic. Eur. J. Oral. Sci. 2010, 118, 396-403. [CrossRef] [PubMed]

16. Kern, M. Resin bonding to oxide ceramics for dental restorations. J. Adhes. Sci. Technol. 2009, 23, $1097-1111$. [CrossRef]

17. Klosa, K.; Warnecke,H.; Kern, M. Effectiveness of protecting a zirconia bonding surface against contaminations using a newly developed protective lacquer. Dent. Mater. 2014, 30, 785-792. [CrossRef]

18. Yang, B.; Scharnberg, M.; Wolfart, S.; Quaas, A.C.; Ludwig, K.; Adelung, R.; Kern, M. Influence of contamination on bonding to zirconia ceramic. J. Biomed. Mater. Res. B Appl. Biomater. 2007, 81, 283-290. [CrossRef]

19. Klosa, K.; Meyer, G.; Kern, M. Clinically used adhesive ceramic bonding methods: A survey in 2007, 2011, and in 2015. Clin. Oral Investig. 2016, 20, 1691-1698. [CrossRef]

20. Price, R.; Sauro, S.; Alex, G. What factors affect long-term bond durability, and how can bond strength be improved? Inside Dent. 2018, 14. digital version.

21. Yoshida, K. Influence of cleaning methods on resin bonding to saliva-contaminated zirconia. J. Esthet. Restor. Dent. 2018, 30, 259-264. [CrossRef]

22. Hannig, C.; Laubach, S.; Hahn, P.; Attin, T. Shear bond strength of repaired adhesive filling materials using different repair procedures. J. Adhes. Dent. 2006, 8, 35-40. [PubMed]

23. Frankenberger, R.; Kramer, N.; Ebert, J.; Lohbauer, U.; Kappel, S.; ten Weges, S.; Petschelt, A. Fatigue behavior of the resin-resin bond of partially replaced resin-based composite restorations. Am. J. Dent. 2003, 16, 17-22. [PubMed] 
24. Stawarczyk, B.; Krawczuk, A.; Ilie, N. Tensile bond strength of resin composite repair in vitro using different surface preparation conditionings to an aged CAD/CAM resin nanoceramic. Clin. Oral. Investig. 2015, 19, 299-308. [CrossRef]

25. Ozcan, M.; Valandro, L.F.; Pereira, S.M.; Amaral, R.; Bottino, M.A.; Pekkan, G. Effect of surface conditioning modalities on the repair bond strength of resin composite to the zirconia core/veneering ceramic complex. J. Adhes. Dent. 2013, 15, 207-210.

26. Saracoglu, A.; Ozcan, M.; Kumbuloglu, O.; Turkun, M. Adhesion of resin composite to hydrofluoric acid-exposed enamel and dentin in repair protocols. Oper. Dent. 2011, 36, 545-553. [CrossRef]

27. Loomans, B.A.; Mine, A.; Roeters, F.J.; Opdam, N.J.; De Munck, J.; Huysmans, M.C.; Van Meerbeek, B. Hydrofluoric acid on dentin should be avoided. Dent. Mater. 2010, 26, 643-649. [CrossRef]

28. Perriard, J.; Lorente, M.C.; Scherrer, S.; Belser, U.C.; Wiskott, H.W. The effect of water storage, elapsed time and contaminants on the bond strength and interfacial polymerization of a nanohybrid composite. J. Adhes. Dent. 2009, 11, 469-478.

29. Hannig, C.; Hahn, P.; Thiele, P.P.; Attin, T. Influence of different repair procedures on bond strength of adhesive filling materials to etched enamel in vitro. Oper. Dent. 2003, 28, 800-807.

30. Chiba, K.; Hosoda, H.; Fusayama, T. The addition of an adhesive composite resin to the same material: Bond strength and clinical techniques. J. Prosthet. Dent. 1989, 61, 669-675. [CrossRef]

31. Martins, N.M.; Schmitt, G.U.; Oliveira, H.L.; Madruga, M.M.; Moraes, R.R.; Cenci, M.S. Contamination of composite resin by glove powder and saliva contaminants: Impact on mechanical properties and incremental layer debonding. Oper. Dent. 2015, 40, 396-402. [CrossRef]

32. Shimazu, K.; Karibe, H.; Ogata, K. Effect of artificial saliva contamination on adhesion of dental restorative materials. Dent. Mater. 2014, 33, 545-550. [CrossRef]

33. Oskoee, S.S.; Navimipour, E.J.; Bahari, M.; Ajami, A.A.; Oskoee, P.A.; Abbasi, N.M. Effect of composite resin contamination with powdered and unpowdered latex gloves on its shear bond strength to bovine dentin. Oper. Dent. 2012, 37, 492-500. [CrossRef]

34. Bonstein, T.; Garlapo, D.; Donarummo, J., Jr.; Bush, P.J. Evaluation of varied repair protocols applied to aged composite resin. J. Adhes. Dent. 2005, 7, 41-49.

35. Kern, M.; Thompson, V.P. Sandblasting and silica coating of a glass-infiltrated alumina ceramic: Volume loss, morphology, and changes in the surface composition. J. Prosthet. Dent. 1994, 71, 453-461. [CrossRef]

36. Khalefa, M.; Finke, C.; Jost-Brinkmann, P.G. Effects of air-polishing devices with different abrasives on bovine primary and second teeth and deciduous human teeth. J. Orofac. Orthop. 2013, 74, 370-380. [CrossRef]

37. Abu Alhaija, E.S.; Al-Wahadni, A.M. Evaluation of shear bond strength with different enamel pre-treatments. Eur. J. Orthod. 2004, 26, 179-184. [CrossRef]

38. Hikita, K.; Van Meerbeek, B.; De Munck, J.; Ikeda, T.; Van Landuyt, K.; Maida, T.; Lambrechts, P.; Peumans, M. Bonding effectiveness of adhesive luting agents to enamel and dentin. Dent. Mater. 2007, 23, 71-80. [CrossRef]

39. Tezvergil, A.; Lassila, L.V.; Vallittu, P.K. Composite-composite repair bond strength: Effect of different adhesion primers. J. Dent. 2003, 31, 521-525. [CrossRef]

40. Kern, M.; Thompson, V.P. Influence of prolonged thermal cycling and water storage on the tensile bond strength of composite to NiCr alloy. Dent. Mater. 1994, 10, 19-25. [CrossRef]

41. Yang, B.; Lange-Jansen, H.C.; Scharnberg, M.; Wolfart, S.; Ludwig, K.; Adelung, R.; Kern, M. Influence of saliva contamination on zirconia ceramic bonding. Dent. Mater. 2008, 24, 508-513. [CrossRef] [PubMed]

42. Grasso, C.A.; Caluori, D.M.; Goldstein, G.R.; Hittelman, E. In vivo evaluation of three cleansing techniques for prepared abutment teeth. J. Prosthet. Dent 2002, 88, 437-441. [CrossRef] [PubMed]

43. Ruyter, I.E.; Sjøvik, I.J. Composition of dental resin and composites. Acta Odontol. Scand. 1981, 39, $133-146$. [CrossRef]

44. Griffiths, B.M.; Watson, T.F.; Sherriff, M. The influence of dentine bonding systems and their handling characteristics on the morphology and micropermeability of the dentine adhesive interface. J. Dent. 1999, 27, 63-71. [CrossRef]

45. Wegner, S.M.; Gerdes, W.; Kern, M. Effect of different artificial aging conditions on ceramic/composite bond strength. Int. J. Prosthodont. 2002, 15, 267-272.

46. Söderholm, K.-J.M.; Roberts, M.J. Influence of water exposure on the tensile strength of composites. J. Dent. Res. 1990, 69, 1812-1816. [CrossRef] 
47. Bitter, K.; Schubert, A.; Neumann, K.; Blunck, U.; Sterzenbach, G.; Ruttermann, S. Are self-adhesive resin cements suitable as core build-up materials? Analyses of maximum load capability, margin integrity, and physical properties. Clin. Oral. Investig. 2016, 20, 1337-1345. [CrossRef]

48. Kumar, L.; Pal, B.; Pujari, P. An assessment of fracture resistance of three composite resin core build-up materials on three prefabricated non-metallic posts, cemented in endodontically treated teeth: An in vitro study. Peer. J. 2015, 3, e795. [CrossRef]

49. Reymus, M.; Roos, M.; Eichberger, M.; Edelhoff, D.; Hickel, R.; Stawarczyk, B. Bonding to new CAD/CAM resin composites: Influence of air abrasion and conditioning agents as pretreatment strategy. Clin. Oral. Investig. 2019, 23, 529-538. [CrossRef]

(C) 2020 by the authors. Licensee MDPI, Basel, Switzerland. This article is an open access article distributed under the terms and conditions of the Creative Commons Attribution (CC BY) license (http://creativecommons.org/licenses/by/4.0/). 